\title{
Studying the parameter gradient energy coefficient of Polyethylene glycol as a function of molecular weight with Freed Contribution
}

\author{
Malak J. Ali ${ }^{* *}$ Saygen M. Nuri²; Shanay Rajab Hasan ${ }^{3}$ \\ ${ }^{1}$ Department of Physics, College of Education for Pure Science, Kirkuk University, Kirkuk, Iraq. \\ ${ }^{2,3}$ Department of Chemical İndustry, North Technical University, Kirkuk, Iraq. \\ Email: ${ }^{1 *}$ Malakjalii91@gmail.com, ${ }^{2}$ Saygin.kuzeci@yahoo.com ${ }^{3}$ Shnay.rajab@yahoo.com
}

(Received September 05, 2019; Accepted October 24, 2019; Available online June 01, 2020)

DOI: 10.33899/edusj.2019.126025.1016, @ 2020, College of Education for Pure Science, University of Mosul.

This is an open access article under the CC BY 4.0 license (http://creativecommons.org/licenses/by/4.0/).

\begin{abstract}
The gradient energy coefficient $(\kappa)$ has a main function in extracting the polymers properties to help us to innovate and manufacture new polymers and different process like coating, wetting, foaming, adhesion operations. The Cahn-Hilliard $(\mathrm{CH})$ theory [1], represents the free energy profile of polymer surfaces or interfaces. Considers the free energy profile of polymer surfaces or interfaces as inhomogeneous which has more than one phase. On the other hand, it has been used the Freed Bawendi contribution in conjunction with Cahn-Hilliard in treatment with architecture structure for polymers [2]. While Simha-Somcynsky (SS) theory describes the thermodynamic properties of both low and high molecular weights in terms of occupied site fraction (y) [3]. This study has been examined in the range of (313 -473) K temperatures and up to about (150) Mpa pressure. The quantitative success of our study is clearly appeared in the minimum and maximum deviations in the volume is 0.036 and 0.128 respectively.
\end{abstract}

Keywords: Simha-Somcynsky, Freed contribution, Cahn- Hilliard, surface tension, molecular weight, entropic coefficients.

$$
\begin{aligned}
& \text { دراسة معامل انحار الطاقة للبولي اثيلين كلايكول كدالة للوزن الجزيئي مع نظرية فريد لتوزيع الجزيئات } \\
& \text { ملاك جعفر علي 1" و صايغن محمد نوري2 و شناي رجب حسن } 3
\end{aligned}
$$

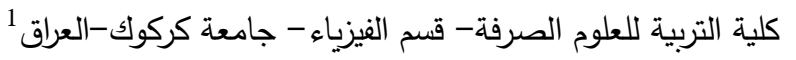

$$
\begin{aligned}
& \text { الجامعة التقنية الثمالية- قسم الصناعة الكيميائية-كركوك-العراق } 3,2
\end{aligned}
$$


ان لمعامل انحدار الطاقة دور رئيسي في في استخراج خصائص البوليمرات ومساعدتا في اكتشاف و تصنيع بوليمرات جديدة باستخدام عمليات مختلفة مثل (الارغاء، الطلاء، الرطوبة، اللواصق، المزج) نظرية كاهن هيلارد تدرس الطاقة الحرة لسطح البوليمر او السطح البيني للبوليمر في المواد غير المتجانسة هذا وبلتزامن مع نظرية فريد في التركيب الهندسية للمقاطع في سلاسل البوليمر لذا تم العمل بهذا البحث ابتداءا من نظرية كاهن هيلارد الذي يمثل الطاق الحرة للسطح الخارجي والداخلي في البوليمر للخليط الغير متجانس. تم دمج نظريتي كاهن هيلارد مع نظرية فريد(الخاص بالتوزيع الهندسي لوحدات البوليمر )للحصول على نتائج دقيقة عن بعض الخواص الثرموديناميكية كالوزن الجزيئي، الثد السطحي، معامل انحدار الطاقة، الكثافة، سك السطح تحت درجات حرارة محصورة بين(313 -473) كلفن وضغط 150ميكا باسكال. من هذه الاهميات هي؛ اوغيرها الكثير. ان معامل انحدار الطاقة يحدد موقع الانحداربالنسبة الى النظام. درجات الحرية الداخلية والخارجية للجزيئات وتفاعلات الجزيئات المركزية في النظريتين ( سمها-سومسينسكي و التوزبع الهندي للجزيئ لفريد وبمساعدة كاهن هيلارد), حيث تم العمل بهذه الدراسة نظريا واثبات صحة النتائج عمليا عن طريق النتائج والحسابات والرسوم البيانية ان نجاح هذه الدراسة ضهرت باصغر قيمة خطا بحدود 0.036 واكبر قيمة خطا بحدود 0.128 الكلمات الدالة: نظرية سيمها سومسينسكي, نظرية فريد في التوزيع, الثد السطحي, نظرية كاهن هيلارد.

\section{Introduction}

The thermodynamic properties can be characterized using the lattice fluid (LF) theory for the high and low molecular weight [2]. The conjunction of the two theories: lattice fluid (LF) with CahnHilliard $(\mathrm{CH})$ is functioned to improve finding the surface tension of the nonpolar and little bit of the polar liquids of a random molecular weight has hold by Poser and Sanchez [4] to calculate and find the surface density profile and surface tension of polymers in a wide range of temperature. For inhomogeneous mixture, the free energy density profile according to Cahn-Hilliard $(\mathrm{CH})$ and within the phase separation when $(\kappa)$ is constant which represents the interaction coefficient or gradient energy coefficient for the component [2]. After an extensively studying on the surface density profile and surface tension of polymers by Dee-Sauer and C. Miqueu and co-workers on the density profile of polymers for a wide range of temperatures by employing the Cahn-Hilliard [5], gradient density In conjunction with Sanchez and Lacombe (SL) [6]. Orwoll, and Vrij (FOV)[7], they gained for the branched, linear n-alkanes the gradient energy coefficient $(\kappa)$ and the surface tension. When the surface tension increases, the entropy of the surface degreases as the molecular weight increases [8]. The bulk properties are connected originally to the hole fraction could frame the relation between surface tension and surface density profile with the hole fraction or free volume of the bulk, that shows that the surface thermodynamics properties are really connected to the bulk properties. The relationship between surface tension and hole fraction of the bulk properties has been studied by Carri and Simha (CS) by means of SS lattice-hole theory [9]. 


\section{Theoretical Formulation}

\subsection{The Simha-Somcynsky (SS)-EOS Theory}

Equation of state (EOS) has been developed by Simha-Somcynsky (SS), which (EOS) based on the lattice-hole model [10] representing the temperature and volume dependent occupied site fraction, $\mathrm{y}(\mathrm{V}, \mathrm{T})$. The occupied site fraction, $\mathrm{y}(\mathrm{V}, \mathrm{T})$, and the complementary hole fraction, $\mathrm{h}(\mathrm{V}$, $\mathrm{T})$, are given by the equation:

$$
y=1-h=\frac{s N}{s N+N_{h}}
$$

(s) Is the segments number in a molecule, $N$ and $N_{h}$ are the number of molecular chain and the number of unoccupied site respectively.

The configurational partition function can be assembly written as:

$$
Z_{\text {conf } .}=g(N, y)\left[v_{f}(y, V)\right]^{3 c} \exp \left(-E_{o}(y, V) / k T\right)
$$

$E_{o}$ Is the total lattice energy of the system employed Lennard-Johns potential energy, $\quad\left(v_{f}\right)$ is the free volume, and $g(N, y)$ is the combinatorial factor which is the total number of distinguishable degenerate arrangements of the holes and molecules by Boltzmann's equation.

The SS-EOS equation, derived from the configurational Helmholtz energy, is

$$
\frac{\tilde{P} \tilde{V}}{\tilde{T}}=\frac{1}{1-\zeta}+\frac{2 y}{\tilde{T}} Q(1.011 Q-1.2045)
$$

The SS theory is formulated in terms of scaled volume, scaled temperature and scaled pressure,

$$
\tilde{V}=\frac{V}{V^{*}}, \quad \tilde{T}=\frac{T}{T^{*}}, \quad \tilde{p}=\frac{p}{p^{*}}
$$

The occupied site fraction can be obtained from the minimization of Helmholtz energy of an ensemble $\partial F /\left.\partial y\right|_{V, T_{C / S}}=0$.

$$
\frac{s}{3 c}\left(\frac{s-1}{s}+\frac{\ln (1-y)}{y}\right)-\left(\frac{\zeta-1 / 3}{1-\zeta}\right)-\frac{y}{6 T} Q[2.409-3.303 Q]=0
$$

Where $Q=(y \tilde{V})^{-2}$ and $\zeta=2^{-1 / 6} y(y \tilde{V})^{-1 / 3}$ 


\subsection{Cahn-Hilliard theory and Freed Contribution}

The thermodynamic characteristic of a system according to Cahn-Hilliard theory is connected with an interface between two noncondensing phases [7]. In the equilibrium state and in the interface between the liquid and gas phases for the pure polymer. The density of the composition is discontinuous or behaves as gradient, take into consideration a binary alloy in equilibrium state of two-phase. For an inhomogeneous system and in the free energy density, the density gradient varies continuously from the bulk (liquid density), to the surface (vapor density), so Helmholtz free energy density, $\alpha$, of any system with an interface can be achieved by employing then expanding Helmholtz free energy around the equilibrium state in Taylor series as below:

$$
\alpha\left(\rho, \nabla \rho, \nabla^{2} \rho \ldots\right)=\alpha_{o}(\rho)+\kappa_{1} \nabla^{2} \rho+\kappa_{2}(\nabla \rho)
$$

$\alpha_{o}(\rho)$ : Is the local free energy density of homogeneous polymer system, while the Laplacian coefficient and gradient density terms are:

$$
k_{1}=\left(\frac{\partial \alpha}{\nabla^{2} \rho}\right)_{o} ; \quad k_{2}=\frac{1}{2}\left(\frac{\partial^{2} \alpha}{\partial(\nabla \rho)^{2}}\right)
$$

previous equation the subscript ${ }_{o}$ ) refers to the derivatives that are limited by the amounts $\nabla \rho$ and $\nabla^{2} \rho$ going to zero. The Helmholtz free energy A, of a system of volume $\mathrm{V}$ is given by:

$$
A=\int_{V}\left[\alpha_{o}(\rho)+k(\nabla \rho)^{2}\right] d V
$$

Here $(k)$ represents the gradient energy coefficient and the theoretıcal value of reduced gradient energy is ( $\tilde{\kappa}=\frac{1}{2}$ ) was extracted by Sutherland-type [12]. Equation (9) contains two terms; the first is the local free energy of homogenous system, while the second term is the composition gradient contribution to the free energy. We can write equation (9) as the final shape for the surface tension of a planar interface as bellow:

$$
\gamma=\int_{-\infty}^{+\infty} \Delta \alpha_{o}+k(\nabla \rho)^{2} d v
$$

$\Delta \alpha_{O}=\alpha_{O}(\rho)-\left(\rho_{l} \mu_{l_{O}}+\rho_{g} \mu_{g_{O}}\right)$ is the difference between the Helmholtz free energy density of the homogenous fluid of density ( $\rho$ ) and two-phase equilibrium mixtures with liquid and gas states. When $\mu_{l_{O}}$ and $\mu_{v_{O}}$ are the chemical potentials of liquid in the equilibrium state and vapor.

After performing some mathematical operations, we get the surface tension as:

$$
\gamma=2 \int_{\rho \nu}^{\rho 1}[\kappa \Delta \alpha(\rho)]^{1 / 2} d \rho
$$


The surface tension and density profile can be obtained directly from the effective parameters if $\kappa$ and $\Delta a$ are famed and can be represented as the following equation [11]:

$$
\gamma=2 \int_{\rho_{g}}^{\rho_{l}}[\kappa \Delta a] d \rho \quad \rightarrow \quad \tilde{\kappa}=\left(\frac{\tilde{\gamma}}{2 \int_{0}^{y_{b}} \sqrt{y \Delta \mu} d y}\right)^{2}
$$

Distinguishable degenerate arrangements of the holes and molecules by Boltzmann's equation. It can be calculated from the mixing entropy of an assembly of molecules and holes as:

$$
\Delta s=k \ln \mathrm{g}(\mathrm{N}, \mathrm{y})
$$

The combinatorial factor is expressed by:

$$
g(N, y) \propto \mathrm{y}^{-N}(1-y)-s N\left(\frac{1-y}{y}\right)
$$

From Boltzmann law and Gibbs free energy at a thermal condition

$$
\Delta s=k \ln \mathrm{g}(\mathrm{N}, \mathrm{y})
$$

$\Delta G=-T \Delta s$

For a binary system (occupied and unoccupied), Gibbs free energy of mixing for the thermal condition (leading to enthalpy of mixing $\left(\Delta H_{m}=0\right.$ At a thermal condition).

\subsection{The Freed contribution}

It was widely believed that the polymer segments in the chains are related randomly according to Cahn-Hilliard theory, but then this theory was studied by Freed Contribution and added information to the polymer chain saying that these chains are in mechanical order structure. To compute freed contribution expression, we use the definition equation of freed contribution which is given by:

$$
\begin{aligned}
& \frac{\Delta S}{N_{l}}=-k \ln g(y, N)+g(y) y(1-y) \\
& g(y)=\sum_{i=0}^{n} a_{i \mathrm{y}} i=a_{o}+a_{1} y+a_{2} y^{2}+\ldots
\end{aligned}
$$

Where $(g)$ is the combinatorial factor, and $(y)$ : is the occupied site fraction using the equation: 


$$
\frac{\Delta S}{N_{\ell}}=a_{o} y(1-y)+a_{1} y^{2}(1-y)+a_{2} y^{3}(1-y)
$$

Where $\left(\begin{array}{lll}a_{o} & a_{1} & a_{2}\end{array}\right)$ are the entropic coefficients. After some substitution and derivation some equations, we add Cahn-Hilliard equation with freed contribution equation as below, so we get:

$$
\begin{aligned}
\frac{\Delta \mu}{k T}= & \left(y_{b}-y_{s}\right)(s-1)+\ln \frac{y_{b}}{y_{s}} \\
& +s a_{0}\left(y_{s}\left(y_{s}-1\right)-y_{b}\left(y_{b}-1\right)\right) \\
& +s a_{1}\left(y_{s}\left(y_{s}-1\right)\left(2 y_{s}-1\right)-y_{b}\left(y_{b}-1\right)\left(2 y_{b}-1\right)\right) \\
& +s a_{2}\left(y_{s}^{2}\left(y_{s}-1\right)\left(3 y_{s}-2\right)-y_{b}^{2}\left(y_{b}-1\right)\left(3 y_{b}-2\right)\right)
\end{aligned}
$$

The values of entropic coefficients obtained by Ugur Yahşi and Mustafa Aslan [13].

$$
\begin{aligned}
& a_{o}=\left(\frac{7-3(-1+s)}{2 s z^{2}}\right)-\left(\frac{-2+s}{s z}\right) \\
& a_{2}=\left(\frac{\left(2(6-5(-1+s))(-1+s)^{2}\right)}{3 s^{3} z^{2}}\right) \\
& a_{1}=\left(\frac{\left(1-6(-1+s)+3(-1+s)^{2}\right)}{s^{2} z^{2}}\right)\left(\frac{(-1+s)^{2}}{s^{2} z}\right)
\end{aligned}
$$

In equation (21), we placed $a_{2}$ before $a_{1}$ because the amounts are from big to small respectively. In equation 3 and 5 if it's taken ( $\tilde{P}=0)$, we will notice the equations will be reduced to $y \tilde{V}=C$ When ( $C$ is constant), and by taking the inverse value of the volume Then the scaled form after the derivation is going to be:

$d \tilde{\rho}=\tilde{C}^{-1} d y$

After some substitutions we get the following equations:

$$
\begin{aligned}
& \Delta \tilde{\alpha}=\Delta \tilde{\mu} d \tilde{\rho} \\
& \Delta \tilde{\alpha}=\tilde{C}^{-1} y \Delta \tilde{\mu}
\end{aligned}
$$

Using the reduced surface tension equation as in equation(24):

$$
\tilde{\gamma}=2 \int_{1-y}^{y}\left[\tilde{\kappa}\left(\tilde{C}^{-1} y\right) \Delta \tilde{\mu}\right]^{1 / 2}\left(C^{-1} d y\right)
$$

Taking the constant values out of the integration from equation (24). Leads to the following equation:

$\tilde{\gamma}=2 \tilde{C}^{-3 / 2} \tilde{\kappa}^{1 / 2} \int_{1-y}^{y}[y \Delta \tilde{\mu}]^{1 / 2} d y$ 


$$
\tilde{\gamma}=2\left(\frac{\tilde{\kappa} \tilde{T}}{\tilde{C}_{y \tilde{V}}}\right)^{1 / 2} \int_{y_{s}}^{y_{b}}\left(y_{s}\left(\begin{array}{c}
\left(y_{b}-y_{s}\right)(s-1)+\ln \frac{y_{b}}{y_{s}}+s a_{0}\left(y_{s}\left(y_{s}-1\right)-y_{b}\left(y_{b}-1\right)\right) \\
+s a_{1}\left(y_{s}\left(y_{s}-1\right)\left(2 y_{s}-1\right)-y_{b}\left(y_{b}-1\right)\left(2 y_{b}-1\right)\right) \\
+s a_{2}\left(y_{s}^{2}\left(y_{s}-1\right)\left(3 y_{s}-2\right)-y_{b}^{2}\left(y_{b}-1\right)\left(3 y_{b}-2\right)\right)
\end{array}\right)\right)^{1 / 2} d y
$$

The reduced gradient energy coefficient can be represented by the following equation:

$$
\tilde{\kappa}=\tilde{\gamma}^{2}\left(\frac{\tilde{C}_{y \tilde{V}}}{4 \tilde{T}}\right)\left(\int_{y_{s}}^{y_{b}}\left(y_{s}\left(\begin{array}{c}
\left(y_{b}-y_{s}\right)(s-1)+\ln \frac{y_{b}}{y_{s}}+s a_{0}\left(y_{s}\left(y_{s}-1\right)-y_{b}\left(y_{b}-1\right)\right) \\
+s a_{1}\left(y_{s}\left(y_{s}-1\right)\left(2 y_{s}-1\right)-y_{b}\left(y_{b}-1\right)\left(2 y_{b}-1\right)\right) \\
+s a_{2}\left(y_{s}^{2}\left(y_{s}-1\right)\left(3 y_{s}-2\right)-y_{b}^{2}\left(y_{b}-1\right)\left(3 y_{b}-2\right)\right)
\end{array}\right)\right) d y\right)^{-1}
$$

It's obtained the reduced surface tension and reduced gradient energy coefficient from $\tilde{\gamma}=\gamma / \gamma^{*}$ and $\tilde{\kappa}=\kappa / \kappa^{*}$ reducing parameter $\gamma^{*}$ and $\kappa^{*}$ is

$\gamma^{*}=\frac{k q_{z} \varepsilon^{*}}{s}\left(v^{*} M\right)^{-2 / 3}$ And $\kappa^{*}=\frac{1}{2} q_{z} M^{2 / 3} k \varepsilon^{*} v^{* 5 / 3}$

Equation (28) gives the theoretical data that has obtained from this study.

\section{Results and Discussion}

In this article, the segments in the polymer chain that depends on the construction after employing Cahn-Hilliard $(\mathrm{CH})$ theory with freed contribution (FC) have been studied. First, we set the parameters (PVT) data; each polymer has its own volume and pressure with the temperature range between (293-473k). The computational programs used in this article are Mathematica and origin. The data were obtained by Mathematica then transfer it to origin program to obtain the graphs. The reduced gradient energy coefficient $(\tilde{\kappa})$ of polyethylene glycol with three molecular weights (302, $693,18500)$, has been studied in this work with the help of freed contribution. Tables (1), (2) and (3) represent Some important thermodynamic parameters of polyethylene glycol with different molecular weights (302), (692) and (18500) which indicates the critical experimental results of reduced gradient energy coefficient, reduced surface tension, the minimum and maximum errors, the occupied and unoccupied site fraction at chosen values of temperature. The experimental results that we obtained in this work are approximately close to our theoretically calculations according to the equation of Carri and Simha (CS) as following [10]:

$$
\gamma(T)=\gamma_{o}\left(1-\frac{T}{T_{C}}\right)^{11 / 9}
$$

$T_{c}$ is the critical temperature and $\gamma_{o}$ is the surface tension at equilibrium state. 
Table (1): Shows the values reduced gradient energy coefficients and reduced surface tension at dıfferent temperatures of Polyethylene Glycol 302.

\begin{tabular}{|c|c|c|c|c|c|c|c|c|}
\hline \multirow{2}{*}{ PEG302 } & \multicolumn{7}{|c|}{ Mini. Err=0.0359 } & \multicolumn{5}{c|}{ Maxi. Err=0.283 } \\
& \multicolumn{2}{|c|}{$T_{c}=864.85$} & \multicolumn{7}{c|}{$\gamma_{0}=75.08$} & 413 & 433 & 453 & 473 \\
\hline $\mathbf{T}(\mathbf{K})$ & 313 & 353 & 373 & 393 & 413 & $0.9595 \pm 0.0024$ \\
& & & & & & & & \\
\hline$\tilde{\gamma}$ & 0.446 & 0.407 & 3870.0 & 0.368 & 0.349 & 0.330 & 0.312 & 0.293 \\
\hline$\tilde{\kappa}$ & 0.120 & 0.110 & 0.107 & 0.105 & 0.095 & 0.090 & 0.085 & 0.079 \\
\hline$h=1-y$ & 0.078 & 0.101 & 0.114 & 0.126 & 0.139 & 0.152 & 0.165 & 0.177 \\
\hline$y V$ & 0.9571 & 0.9582 & 0.9587 & 0.9592 & 0.9598 & 0.9604 & 0.9609 & 0.9616 \\
\hline
\end{tabular}

Table (2): Shows the values reduced gradient energy coefficients and reduced surface tension at different temperatures of Polyethylene Glycol 692.

\begin{tabular}{|c|c|c|c|c|c|c|c|c|}
\hline \multirow{2}{*}{ PEG692 } & \multicolumn{7}{|c|}{ Mini. Err=0.0345 } & \multicolumn{3}{c|}{ Maxi. Err=0.157 } \\
& \multicolumn{2}{|c}{$T_{c}=868.4$} & \multicolumn{7}{c|}{$\gamma_{0}=74.93$} & 413 & \\
\hline T(K) & 313 & 353 & 373 & 393 & 413 & 433 & 453 & 473 \\
\hline$\tilde{\gamma}$ & 0.803 & 0.733 & 6980.0 & 0.664 & 0.630 & 0.596 & 0.563 & 0.530 \\
\hline$\tilde{\kappa}$ & 0.172 & 0.158 & 0.151 & 0.144 & 0.137 & 0.130 & 0.123 & 0.115 \\
\hline$h=1-y$ & 0.079 & 0.103 & 0.115 & 0.128 & 0.140 & 0.153 & 0.166 & 0.179 \\
\hline$y V$ & 0.9575 & 0.9586 & 0.9591 & 0.9597 & 0.9604 & 0.9610 & 0.9616 & 0.9623 \\
\hline
\end{tabular}


Table (3): Shows the values reduced gradient energy coefficients and reduced surface tension at different temperatures of Polyethylene Glycol 18500.

\begin{tabular}{|c|c|c|c|c|c|c|c|c|}
\hline \multirow{2}{*}{ PEG18500 } & \multicolumn{4}{|c}{ Mini. Err=0.036 } & \multicolumn{4}{c|}{ Maxi. Err=0.128 } \\
& \multicolumn{3}{|c|}{$T_{c}=962.01$} & \multicolumn{2}{c|}{$\gamma_{0}=69.01$} & \multicolumn{2}{c|}{$\langle y V\rangle=0.9601 \pm 0.0025$} \\
\hline T(K) & 313 & 353 & 373 & 393 & 413 & 433 & 453 & 473 \\
\hline$\tilde{\gamma}$ & 7.078 & 0.407 & 3870.0 & 0.368 & 0.349 & 0.330 & 0.312 & 0.293 \\
\hline$\tilde{\kappa}$ & 0.512 & 0.509 & 0.501 & 0.430 & 0.402 & 0.395 & 0.371 & 0.256 \\
\hline$h=1-y$ & 0.076 & 0.099 & 0.111 & 0.123 & 0.135 & 0.147 & 0.159 & 0.172 \\
\hline$y V$ & 0.9575 & 0.9586 & 0.9592 & 0.9597 & 0.9604 & 0.9610 & 0.9616 & 0.9623 \\
\hline
\end{tabular}

In tables (1), (2), (3) we can clearly see that the reduced gradient energy coefficient in our Experimental results is approximately the same as the theoretical calculation according to Sutherland-type ( $\tilde{\kappa}=0.5)$ [12] especially in the high molecular weights in (PEG18500). While it reduces gradually in (PEG692, PEG302)

Table (4): The experimental values of number of segments, number of contacts between segments, of different molecular weights of Polyethylene Glycol.

\begin{tabular}{|c|c|c|c|c|c|c|c|c|c|}
\hline Polymers & $\mathbf{S}$ & $P^{*}(\mathrm{Mpa})$ & $T^{*}(K)$ & $\begin{array}{l}10^{-3} v^{*} \\
\mathrm{~cm}^{3} / g\end{array}$ & $\begin{array}{c}10^{-4} \kappa^{*} \\
\left(\mathrm{erg} \mathrm{cm}^{5} / \mathrm{gr}^{2}\right)\end{array}$ & $\begin{array}{l}10^{-2} \gamma^{*} \\
\mathrm{erg} / \mathrm{cm}^{2}\end{array}$ & $\varepsilon^{*}(K)$ & $10^{6} v^{*}$ & $\boldsymbol{q}_{z}$ \\
\hline PEG302 & 8.375 & 1080.72 & 9274.7 & 0.850 & 0.445 & 9.71 & 389.7 & 30.678 & 86 \\
\hline PEG692 & 19.2 & 1038.23 & 9138.3 & 0.866 & 1.798 & 5.39 & 386.25 & 31.244 & 192. \\
\hline PEG18500 & 513.14 & 1035.5 & 9268.6 & 0.868 & 413.103 & 0.627 & 389.99 & 31.324 & 5132 \\
\hline
\end{tabular}




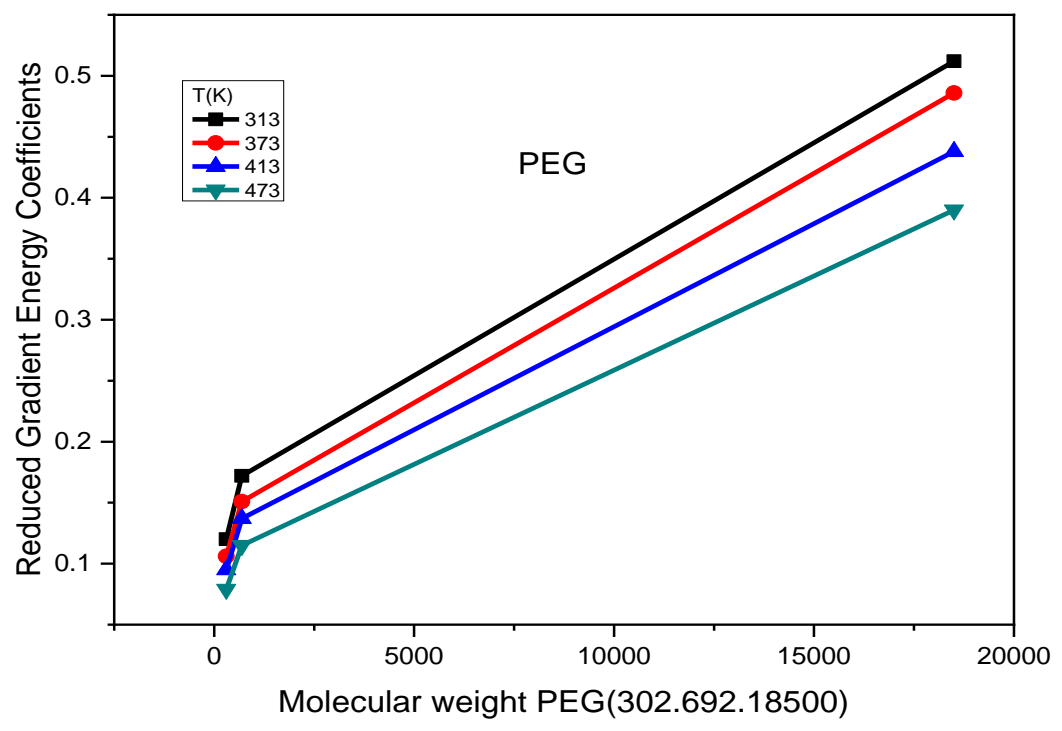

\section{Figure (1): Plot of reduced gradient energy coefficient as a function of molecular weight.}

It shows clearly the relation between the gradient energy coefficient $(\tilde{\kappa})$ and they molecular weight $\left(\mu_{\omega}\right)$ of different PEG compounds, there is a rapid raise in the $\tilde{\kappa}$ at low values of $\mu_{\omega}$. However, from 500 of $\mu_{\omega}$ and above the $\tilde{\kappa}$ start to increase linearly at a lower rate.

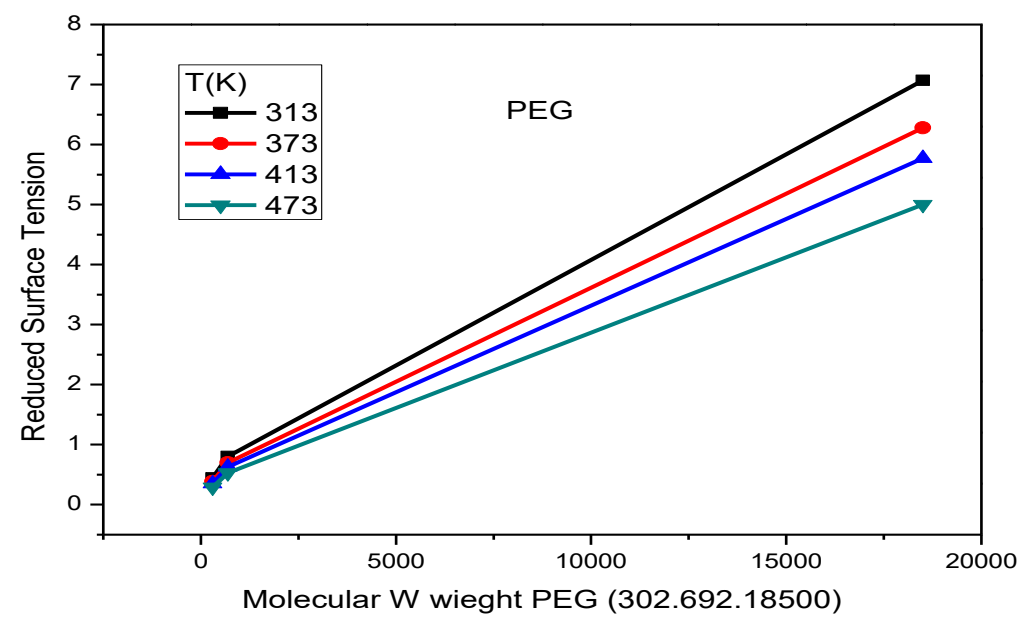

Figure (2): Plot of reduced surface tension as a function of molecular weight.

We can obviously tell that increasing the molecular weight leads to increase the surface tension. The correlation in figure (3) is direct proportion which means that increasing of the surface tension $(\tilde{\gamma})$ leads to the increasing of the gradient energy coefficient $(\tilde{\kappa})$. 


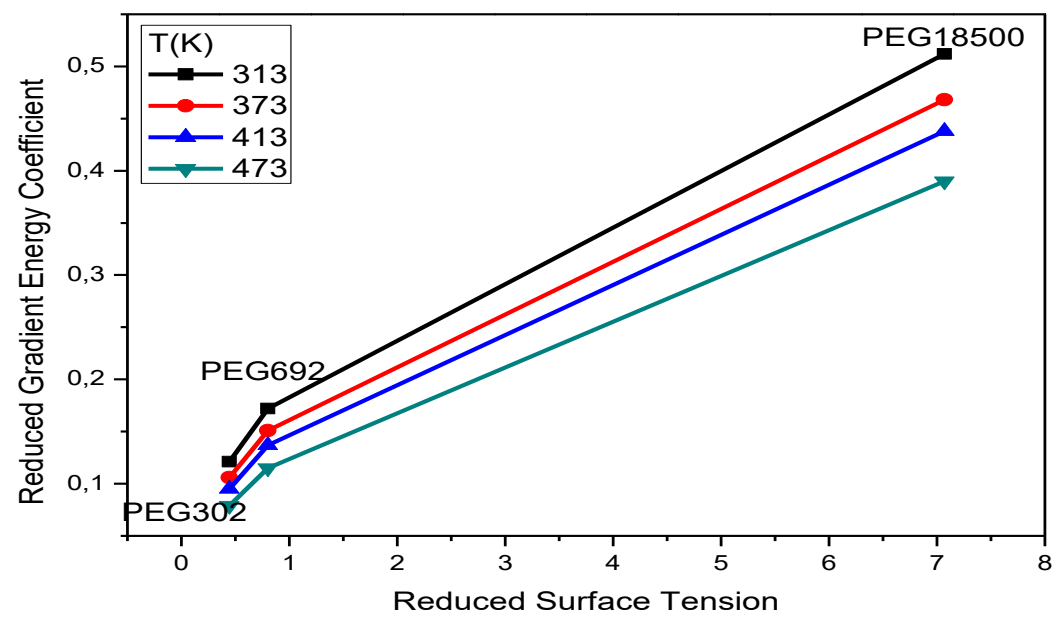

Figure (3): Plot of reduced gradient energy coefficient as a function of reduced surface tension

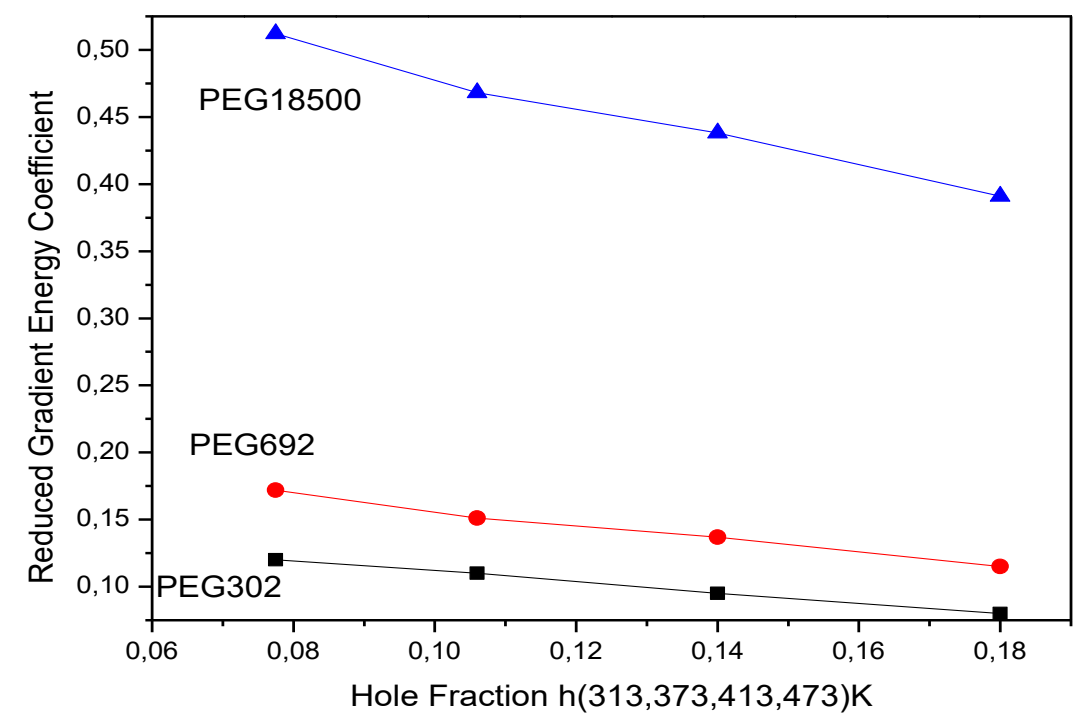

Figure (4): Plot of reduced gradient energy coefficient as a function of hole fraction 


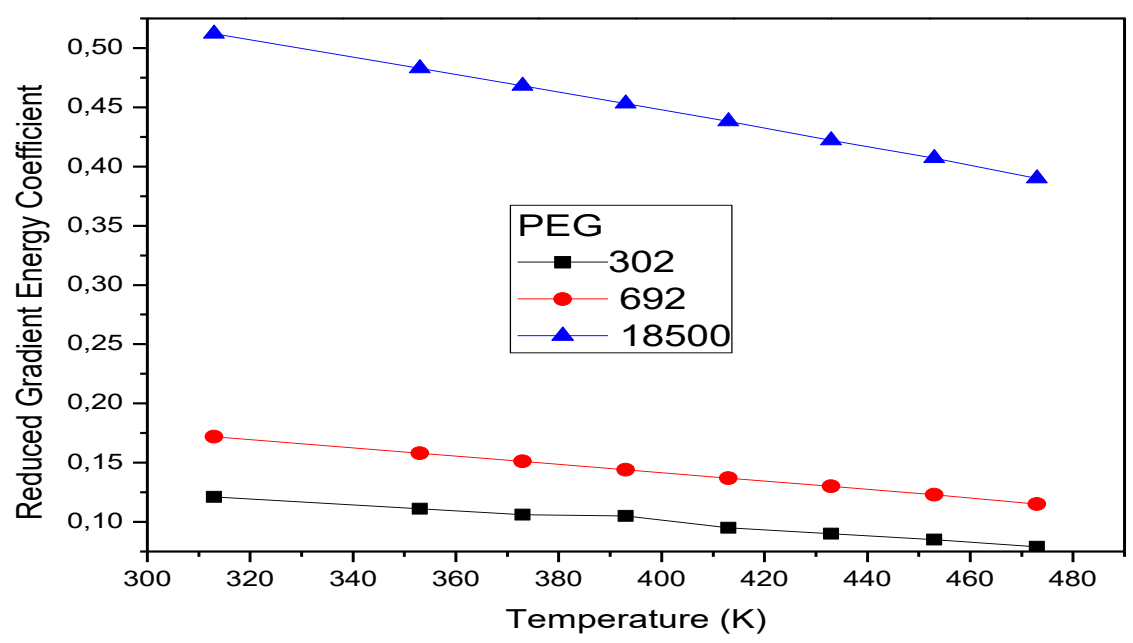

Figure (5): Plot of reduced gradient energy coefficient as a function of temperature

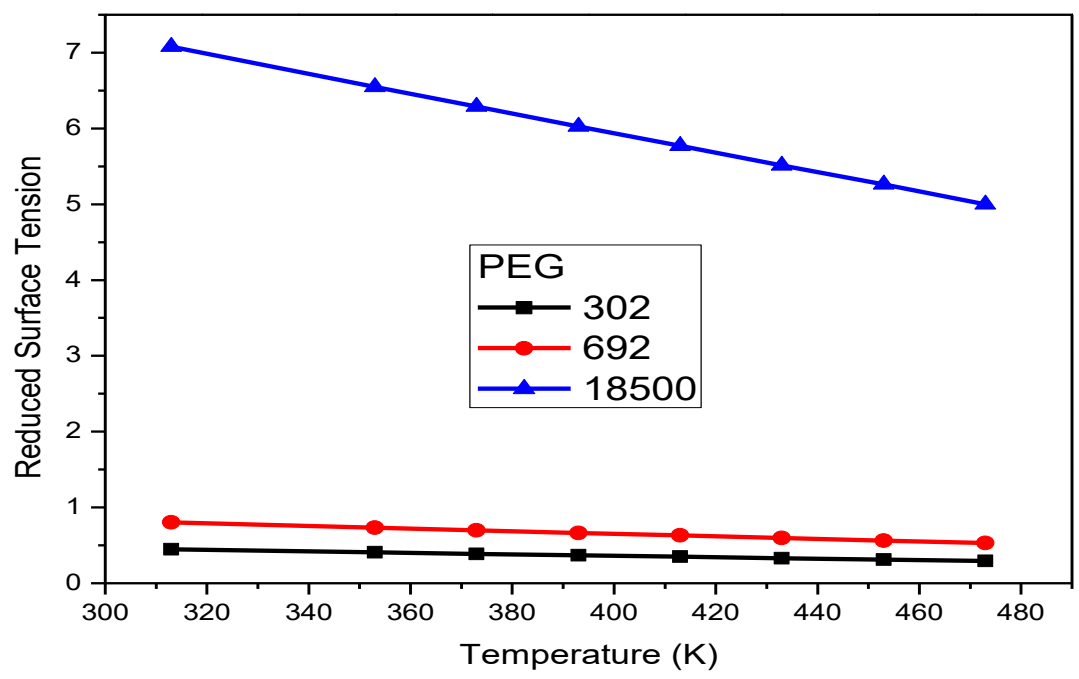

Figure (6): Plot of reduced surface tension as a function of temperature

The variation of the hole fraction with gradient energy coefficient is illustrated in figure (4), which reveals the gradual decrease of the gradient energy coefficient as the molecular weight decreases. Figure (5) shows the relation between the gradient energy coefficients $(\tilde{\kappa})$ as a function of temperature, which decrease as the temperature increase because of the raise of interaction coefficient between the molecules. Figure (6) describes the sketch of temperature as a function of the reduced surface tension, which means that the surface tension $(\tilde{\gamma})$ degrease as the temperature degrees and they decrease proportionally from the high molecules to the low molecules. 
This work adds important information to science showing that the molecular weight is related strongly with the scaled gradient energy coefficient that refers to the line segment or the number segment (s).

\section{Conclusion}

We have examined in this task the gradient energy coefficient as a function of some parameters like polyethylene glycol PEG (302), PEG (692), PEG (18500) that shows our work can be applied on the high and low molecular weights. This study can be employed to the other polymers like: polypropylene glycol, polypropylene glycol, poly dimethyl siloxane etc. It has been found that the surface tension weakened as the temperature rises up gradually, and the gradient energy coefficient is related directly to the molecular weight which refers to the stretched in the length of segments and leads to increase the surface intensity. We have studied one model which is polyethylene glycol with its three molecular weights three and our idea can be applied to all polymers. And find the other easy characteristic easily.

\section{LIST OF SYMBOLS AND ABBREVIATION}

\begin{tabular}{|c|c|}
\hline Abbreviation & Key \\
\hline $\mathrm{g}$ & Combinatorial factor \\
\hline $\mathrm{N}$ & Number of molecule \\
\hline $\mathrm{y}$ & Occupied site fraction \\
\hline$\gamma$ & surface tension \\
\hline$\tilde{\gamma}$ & reduced surface tension \\
\hline$\gamma_{0}$ & surface tension at equilibrium \\
\hline $\mathrm{I}$ & Euler equation \\
\hline$P^{*} T^{*} v^{*} \varepsilon^{*}$ & The characteristic parameters (Pa, $\left.m^{3}, \mathrm{~K}, \mathrm{k} . \mathrm{K}\right)$ \\
\hline$a_{0}, a_{1}, a_{2}$ & The entropic coefficients \\
\hline$q_{z}$ & Number of contract between segments \\
\hline$T_{c}$ & The temperature at equilibrium state (k) \\
\hline $\mathrm{K}$ & Boltzmann constant (J/k) \\
\hline
\end{tabular}


Journal of Education and Science (ISSN 1812-125X), Vol: 29, No: 2, 2020 (201-215)

\begin{tabular}{|c|c|}
\hline $\mathrm{T}$ & Temperature ((Kelvin) \\
\hline$\rho$ & Surface density \\
\hline$\kappa$ & Gradient energy coefficient \\
\hline$\widetilde{\kappa}$ & reduced gradient energy coefficient \\
\hline$E_{o}$ & The lattice energy \\
\hline$\alpha$ & Helmholtz free energy density \\
\hline$\zeta$ & Coherence length \\
\hline $\mathrm{s}$ & Is the segments number in a molecule \\
\hline$v_{f}$ & the free volume $m^{3} /$ mol \\
\hline$\alpha_{o}(\rho)$ & the local free energy density of homogeneous polymer system \\
\hline$\mu_{1_{o}}$ and $\mu_{v_{o}}$ & Are the chemical potentials of liquid in the equilibrium state and vapor. \\
\hline $\mathrm{A}$ & The Helmholtz free energy \\
\hline$\Delta G$ & Gibbs free energy \\
\hline$T_{c}$ & The critical temperature. \\
\hline$\mu_{\omega}$ & The molecular weight \\
\hline
\end{tabular}

\section{References}

1. (Cahn, John W., and John E. Hilliard. The Journal of chemical physics 28, no. 2,258267(1958)).

2. (Freed, Karl F., and Jacek Dudowicz. The Journal of chemical physics 110, no. 2: 13071312) (1999)).

3. (Simha, Robert, and Thomas Somcynsky. Macromolecules 2, no. 4,342-350(1969)).

4. (Poser C.I., and Sanchez; Colloid interface Sci. J. Chem. Phys 69: p.1307-1312, (1989)). 
5. (Sauer B.B., Dee G.T., Miqueu C., Mendiboure B., Graciaa C., Lachasise J., J. Modeling of the surface J. Chem. Phys, 95, p6749, (1991)).

6. Carri G. A. and Simha R. J., Colloid Interface Sci.J. Phys. 178, p 483-494(1996).

7. (Sperling L.H., "Handbook of Introduction to physical polymer science"- John Wiley \& Sons, Inc., $4^{\text {th }}$ ed, New Jersey (2006)).

8. (Buta, Dorel, and Karl F. Freed. The Journal of chemical physics 116, no. 24.1095910966(2002)).

9. (Utraki L.A.; Simha, Macromol R., J, Chem. Phys., Mol. Theory Simol., no.10, p.17(2000)).

10. (Jain, Raj K., and Robert Simha. Journal of colloid and interface science 216, no. 2.424428(1999)).

11. (Kahl, Heike, and Sabine Enders. Fluid Phase Equilibria 172, no. 1 27-42(2000)).

12. (Poser, C.I. and Sanchez. Journal of Colloid and Interface Science, 69(3), pp.539-548) 1979).

13.(Aslan, M., Ph.D. thesis, Yashi, U. Marmara University. Istanbul. P.17-27(2009)) 